\title{
Satisfaction of hospitalized psychiatry patients: why should clinicians care?
}

\author{
This article was published in the following Dove Press journal: \\ Patient Preference and Adherence \\ 25 April 2014 \\ Number of times this article has been viewed
}

\author{
Xavier-Yves Zendjidjian ${ }^{1,2}$ \\ Karine Baumstarck' \\ Pascal Auquier' \\ Anderson Loundou' \\ Christophe Lançon ${ }^{1,2}$ \\ Laurent Boyer'
}

'Public Health, Chronic Diseases and Quality of Life Research Unit, Aix-Marseille Université, ${ }^{2}$ Department of Psychiatry, La Conception Hospital,

Marseille, France
Correspondence: Xavier-Yves Zendjidjian Public Health, Chronic Diseases and Quality of Life Research Unit, Aix-Marseille Université,

27, bd Jean Moulin 13385 Marseille

Cedex 05, France

$\mathrm{Tel}+3367678$ I 383

Fax +33491435115

Email xavier.zendjidjian@ap-hm.fr
Background: The aim of this study was to determine the relationship between inpatient satisfaction and health outcomes, quality of life, and adherence to treatment in a sample of patients with schizophrenia, while considering key sociodemographic and clinical confounding factors.

Methods: This cross-sectional study was conducted in the psychiatric departments of two public university hospitals in France. The data collected included sociodemographic information, clinical characteristics, quality of life (using the 36-Item Short Form Health Survey), nonadherence to treatment (Medication Adherence Report Scale), and satisfaction (a specific self-administered questionnaire based exclusively on patient point of view [Satispsy-22] and a generic questionnaire for hospitalized patients [QSH]). Multiple linear regressions were performed to assess the associations between satisfaction and quality of life and between satisfaction and nonadherence. Two sets of models were performed, ie, scores on the Satispsy-22 and scores on the QSH.

Results: Ninety-one patients with schizophrenia were enrolled. After adjustment for confounding factors, patients with better personal experience during hospitalization (Satispsy-22) had a better psychological quality of life (SF36-mental composite score, $\beta=0.37 ; P=0.004$ ), and patients with higher levels of satisfaction with quality of care (Satispsy-22) showed better adherence to treatment (Medication Adherence Report Scale total score, $\beta=-0.32 ; P=0.021$ ). Higher QSH scores for staff and structure index were linked to better adherence with treatment (respectively, $\beta=-0.33 ; P=0.019$ and $\beta=-0.30 ; P=0.032$ ), but not with quality of life.

Conclusion: Satisfaction was the only factor associated with quality of life and was one of the most important features associated with nonadherence. These findings confirm that satisfaction with hospitalization should not be neglected in clinical practice and that it may improve the management of patients with schizophrenia.

Keywords: schizophrenia, satisfaction, health outcome, inpatient, hospital, psychiatry, adherence, quality of life

\section{Introduction}

Patients' perception of health care has gained increasing attention in mental health services in recent decades. ${ }^{1,2}$ It is now widely recognized that symptomatic evaluation does not reflect all of the facets that patients consider to be important in their life ${ }^{3-5}$ and that patients' views should supplement the usual indicators of quality in mental health care. ${ }^{6}$ In this context, patient satisfaction has been recognized by public health authorities as an important outcome in the assessment and improvement of the quality of health care for hospitalized persons. ${ }^{7}$ In accordance with French legislation, ${ }^{8}$ inpatient satisfaction has been routinely assessed in psychiatric hospitals using satisfaction questionnaires. However, patient-based surveys are not systematically taken into account by care providers during routine practice. ${ }^{9}$ More research is necessary to convince care providers of the clinical relevance of inpatient satisfaction instruments and thereby increase the use of satisfaction measures as part of clinical decision-making in hospitals. 
Studies of the clinical relevance of satisfaction instruments are scarce, especially in psychiatry. Satisfaction with inpatient care should predict future behaviors, including better follow-up and continuity of outpatient care after hospitalization. ${ }^{10-13}$ More satisfied patients appear also to have better health outcomes after discharge from hospital, ${ }^{14}$ reducing the likelihood of relapse and readmission to hospital. ${ }^{12}$ One limitation of these studies is that the satisfaction questionnaires used were mostly generic ones intended for patients with medical or surgical care, or specific questionnaires derived directly from the literature or experts. ${ }^{2,15}$ Because patients with mental disorders have specific and different expectations regarding their hospitalization, generic instruments may not be relevant in psychiatry. ${ }^{10}$ It is also generally accepted that the content of specific measures should be derived directly from patients' views. ${ }^{16}$ Moreover, the relationship between inpatient satisfaction and important health outcomes, such as quality of life and adherence to treatment, has been minimally explored.

The aim of the present study was to determine the relationship between inpatient satisfaction and health outcomes, quality of life, and adherence to treatment in a sample of patients with schizophrenia, while considering key sociodemographic and clinical confounding factors.

\section{Materials and methods}

In this study, patient satisfaction was assessed using both a specific self-administered questionnaire based exclusively on patient point of view (Satispsy-22) ${ }^{17}$ and a generic questionnaire for hospitalized patients (QSH). ${ }^{7}$

\section{Study design and population}

This cross-sectional study was conducted in the psychiatric departments of two French public university teaching hospitals in Marseille (La Conception Hospital and SainteMarguerite Hospital) over a 3-month period. Eligible patients were defined as adults (ie, age over 18 years) hospitalized for at least 24 hours, with a diagnosis of schizophrenia according to the International Classification of Diseases, version 10 (ICD-10), able to provide informed consent to participate, and French as their native language. Exclusion criteria included a diagnosis other than schizophrenia (eg, schizoaffective disorder) and mental retardation. On the day of discharge, research assistants invited each patient to participate, explaining the purpose of the study. The study was carried out in accordance with the principles of the Declaration of Helsinki. ${ }^{18}$ All subjects gave their informed consent. The Commission Nationale de l'Informatique et des Libertés approved the study (approval number 909318v1).

\section{Data collection}

The following data were collected:

1. Sociodemographic information, including age, sex, and educational level.

2. Clinical characteristics, whereby the severity of the patient's illness at the time of discharge was evaluated using the Clinical Global Impression-Severity scale, ${ }^{19}$ which ranges from 1 (normal) through to 7 (amongst the most severely ill). Functioning of the patient at the time of discharge was assessed on the Global Assessment Functioning (GAF) scale, ${ }^{20}$ which assigns a clinical judgment to the overall functioning level of the individual (ie, psychological, social, and occupational/school functioning), and ranges from 0 (inadequate information) to 100 (superior functioning).

3. Satisfaction of hospitalized patients, measured using the French version of the Satispsy-22, a specific, short, self-administered and multidimensional satisfaction questionnaire designed for people with a mental disorder ${ }^{17}$ (Supplement 1). It is composed of 22 items that describe six dimensions during hospitalization, ie, satisfaction with staff (seven items), quality of care (five items), personal experience (four items), information (two items), activity (two items), and food (two items). The Satispsy-22 also included a total score (index). Dimension and index scores range from 0 , indicating the lowest satisfaction, to 100, indicating the highest satisfaction. The QSH is a generic questionnaire comprising 37 items and leading to two composite scores (staff and structure index, Supplement 2). Each composite score ranges from 0 (lowest satisfaction) to 100 (highest satisfaction). ${ }^{7}$ For the two questionnaires, scores of dimensions were computed if at least half of the contributive items were answered.

4. Quality of life, assessed using the 36-Item Short Form Health Survey (SF36), ${ }^{21}$ which is a generic, self-administered quality of life questionnaire consisting of 36 items describing two composite scores, ie, the physical composite score (SF36-PCS) and the mental composite score (SF36-MCS). Each composite score ranges from 0 (low quality of life level) to 100 (high quality of life level).

5. Nonadherence was assessed using the Medication Adherence Rating Scale (MARS), ${ }^{22}$ which is a ten-item yes/no (1/0) self-reporting multidimensional instrument describing three dimensions, ie, "medication adherence behavior" (items 1-4), "attitude towards taking medication" (items 5-8), and "negative side effects and attitudes to psychotropic medication" (items 9 and 10). Scores for each dimension were obtained by summing the items within each dimension. 


\section{Statistical analyses}

Descriptive statistics for the sample included frequencies and percentages of categorical variables and means and standard deviations of continuous variables. Associations of satisfaction (Satispsy-22 and QSH) with quality of life (SF36) and nonadherence (MARS) were analyzed using Pearson's correlation tests.

Multiple linear regressions were performed to assess the association between satisfaction and quality of life and nonadherence. Each score of the SF36 (SF36-PCS and SF36-MCS) and MARS (medication adherence behavior, attitude toward taking medication and negative side effects, and attitudes to psychotropic medication) was considered as a separate dependent variable. An initial series of models included the six dimensions of the Satispsy-22, and a second series included the two indices of the QSH as independent variables. Satisfaction scores (Satispsy-22 and QSH) were selected based on a threshold $P$-value $\leq 0.05$ as calculated from the univariate analyses. A set of additional variables (sex, age, Clinical Global Impression-Severity scale, and GAF) was included in the models as confounding factors.
The final models incorporated the standardized beta coefficients, which represent a change in the standard deviation of the dependent variable resulting from a change of one standard deviation in the various independent variables. Statistical significance was defined as $P<0.05$. Data analyses were performed using PASW 17.0.2 software (SPSS Inc, Chicago, IL, USA).

\section{Results Sample characteristics}

Ninety-one patients with schizophrenia were enrolled in the study. The mean age was $45.7 \pm 15.2$ years, and 45 (49.5\%) of the subjects were women. The relevant patient details are presented in Table 1.

\section{Correlations of satisfaction with quality of life and nonadherence to treatment}

The correlations of satisfaction scores (ie, Satispsy-22 and QSH) with quality of life scores (SF36-PCS and SF36-MCS) and nonadherence with treatment scores (MARS) are detailed in Table 2.

Table I Sample characteristics

\begin{tabular}{|c|c|c|}
\hline & & $\mathbf{N}=91$ \\
\hline Sociodemographic characteristics & & $\mathbf{N}(\%)$ \\
\hline \multirow[t]{2}{*}{ Sex } & Men & $46(50.5)$ \\
\hline & Women & $45(49.5)$ \\
\hline Age, years & $M \pm S D$ & $45.7 \pm 15.2$ \\
\hline \multirow[t]{2}{*}{ Educational level } & $<12$ years & $35(42.2)$ \\
\hline & $\geq 12$ years & $48(57.8)$ \\
\hline Clinical characteristics & & $\mathbf{M} \pm \mathbf{S D}$ \\
\hline CGI-S (I-7) & & $4.9 \pm 1.2$ \\
\hline GAF $(1-100)$ & & $52.6 \pm 15.2$ \\
\hline Satisfaction & & $\mathbf{M} \pm \mathbf{S D}$ \\
\hline Satispsy-22 scores & Satisfaction with staff & $76.0 \pm 21.2$ \\
\hline \multirow[t]{6}{*}{$(0-100)$} & Quality of care & $73.1 \pm 21.9$ \\
\hline & Personal experience & $50.6 \pm 25.0$ \\
\hline & Information & $68.4 \pm 25.1$ \\
\hline & Activity & $57.8 \pm 27.7$ \\
\hline & Food & $65.3 \pm 24.9$ \\
\hline & Index & $67.0 \pm 14.0$ \\
\hline QSH scores & Staff index & $77.0 \pm 10.6$ \\
\hline$(0-100)$ & Structure index & $73.7 \pm \mid 4.1$ \\
\hline Quality of life and nonadherence & & $\mathbf{M} \pm \mathbf{S D}$ \\
\hline SF36 scores & SF36-PCS & $46.7 \pm 7.2$ \\
\hline$(0-100)$ & SF36-MCS & $36.3 \pm 10.6$ \\
\hline \multirow[t]{3}{*}{ MARS scores } & Medication adherence behavior $(0-4)$ & $0.9 \pm 1.0$ \\
\hline & Attitude toward taking medication $(0-4)$ & $1.2 \pm 1.1$ \\
\hline & Negative side effects and attitudes to & $0.5 \pm 0.8$ \\
\hline
\end{tabular}

Abbreviations: CGI-S, Clinical Global Impression-Severity scale; GAF, Global Assessment Functioning (functioning of patient at the time of discharge); MARS, Medication Adherence Rating Scale; SF36, 36-Item Short Form Health Survey; SF36-PCS, physical composite score; SF36-MCS, mental composite score; QSH, questionnaire for satisfaction of hospitalized patients; Satispsy-22, satisfaction in psychiatry questionnaire; M, mean; SD, standard deviation. 


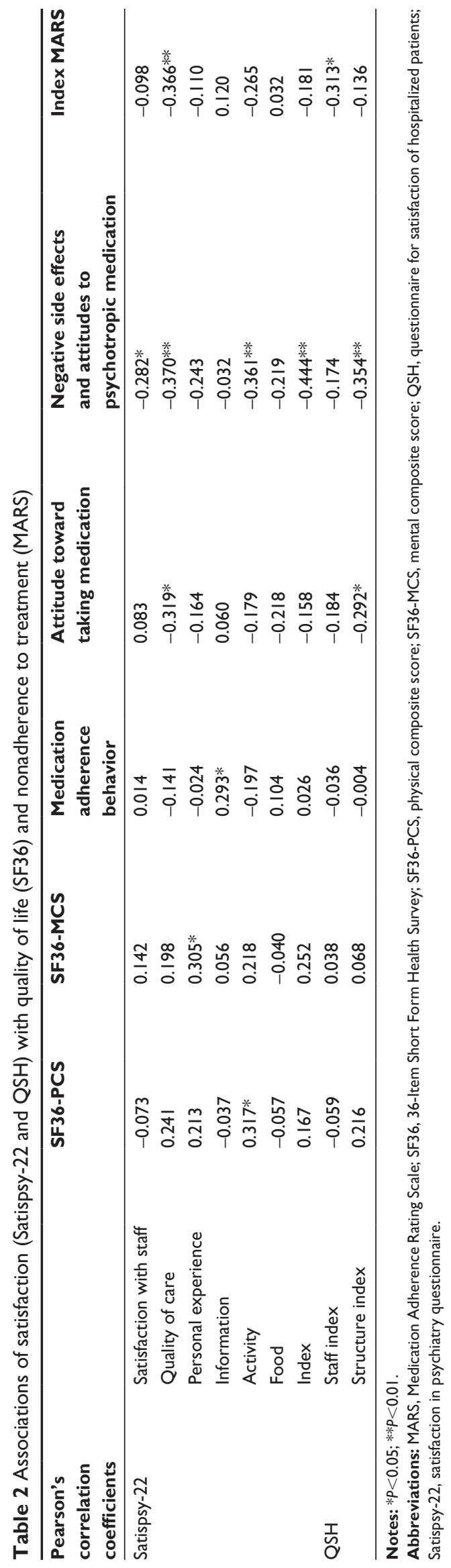

\section{Relationships between satisfaction and quality of life}

In the multiple regression analyses, we found that patients with relatively better personal experiences during hospitalization (Satispsy-22) had a significantly better psychological quality of life (SF36-MCS). In contrast, we did not find any significant link between QSH and SF36 scores. Sociodemographic and clinical parameters were not related to the two summary scores of the SF36. The results are presented in Table 3.

\section{Relationships between satisfaction and nonadherence to treatment}

In the multiple regression analyses, we did not find any significant result between the Satispsy-22 and the first dimension of the MARS (ie, medication adherence behavior). However, patients with a higher level of satisfaction with quality of care (Satispsy-22) had lower scores for two other dimensions (ie, attitude toward taking medication and negative side effects and attitudes to psychotropic medication) and the index of the MARS. The structure index of the QSH was significantly associated with the negative side effects and attitudes toward psychotropic medication dimension of the MARS, and the staff index was associated with the MARS index. Finally, men and individuals with relatively better functioning (higher GAF score) had better adherence to treatment (lower MARS score).

\section{Discussion}

Satisfaction surveys are primarily used by hospital managers who mainly act in the physical environment. The other dimensions of satisfaction related to care are underused by care providers, especially in psychiatry. ${ }^{23}$ The results are insufficiently disseminated by ward managers and insufficiently discussed within teams to develop any improvement programs. ${ }^{9}$ The present study aims to be an initial step to convince clinicians of the relevance of satisfaction surveys.

The primary finding of our study is that satisfaction was the only factor associated with quality of life after adjustment for main confounding factors, contrary to other traditional factors such as the severity of symptoms or the functioning of patients. This finding may trigger a real interest among care providers. Indeed, quality of life measurements are increasingly considered by clinicians to be an important means of evaluating the treatments and care provided to patients with schizophrenia. ${ }^{1,6}$ Moreover, quality of life in particular, as assessed by the SF36, has been reported as an independent predictor of relapse after a 24-month follow-up 


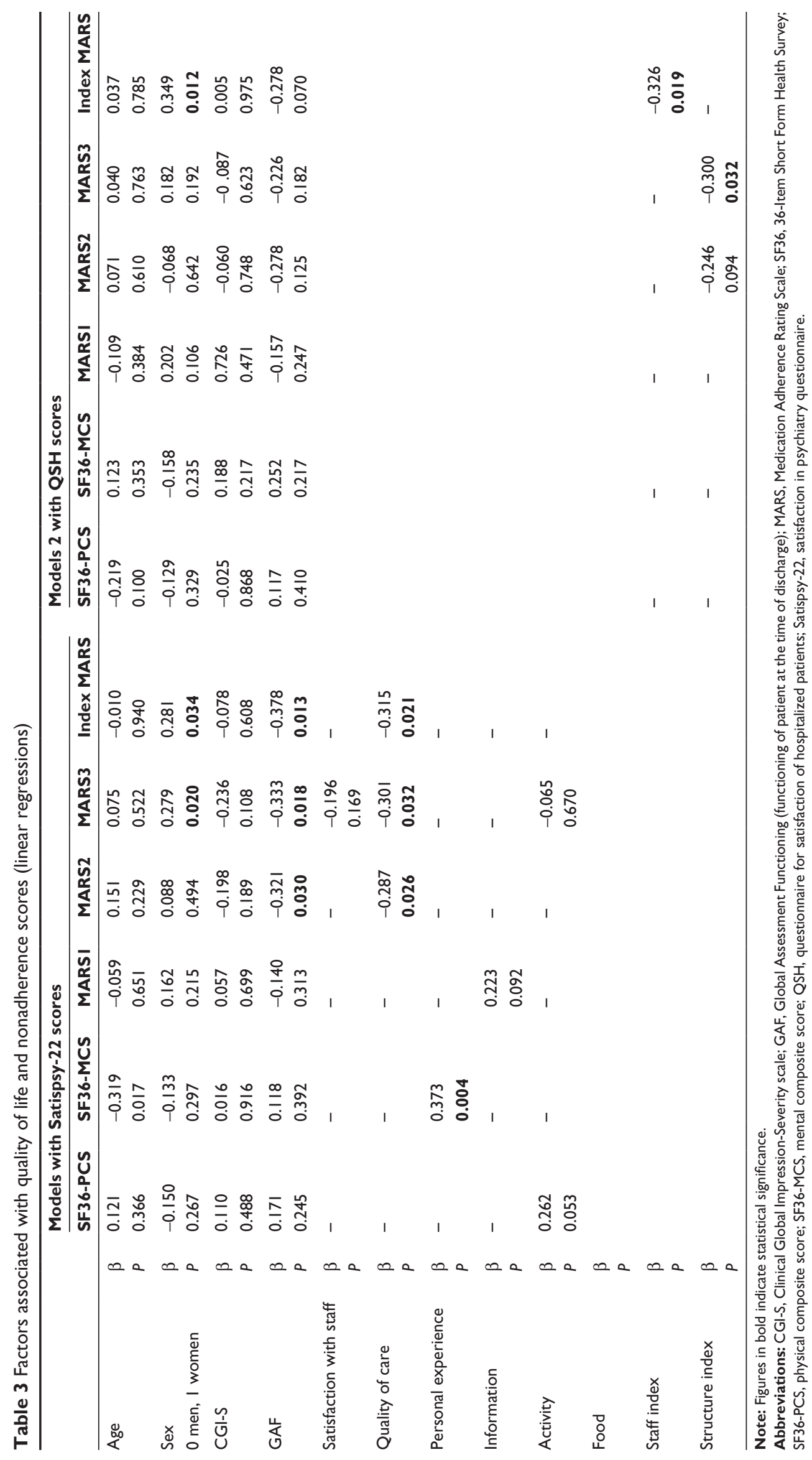


in patients with schizophrenia. ${ }^{24}$ Because the prevention of relapse is a major challenge in the care of patients with schizophrenia, satisfaction measures could be used to develop effective strategies for impacting the quality of life of affected individuals and, consequently, prevent relapse after hospitalization.

The second important finding is that satisfaction was also associated with adherence of patients to treatment. This finding is consistent with the previous finding. Although the importance of maintenance therapy has been well established, nonadherence to medication remains a challenge in schizophrenia. ${ }^{25,26}$ Nonadherence worsens symptoms, increases the risk of suicidal attempts, and consequently increases the likelihood of emergency room visits and rehospitalization. ${ }^{27}$ Patient satisfaction should thus be considered for the development of strategies to enhance medication adherence.

Thirdly, the Satispsy-22 was more strongly associated with quality of life and nonadherence than the QSH. Using a specific multidimensional questionnaire based on the patient's point of view such as the Satispsy-22 may be more informative and relevant than using the generic satisfaction instruments commonly used in psychiatry. ${ }^{2}$ Indeed, specific instruments are potentially more responsive and more sensitive for detecting and quantifying small changes in disease state than generic health status measures. ${ }^{28,29}$ Patients hospitalized in psychiatry units were fully involved in the process of generation, selection, and validation of items in the Satispsy-22. As a consequence, its content encompasses experiences of great importance to patients and is substantially different from generic satisfaction instruments. Our findings suggest that various characterizations of satisfaction should be assessed using specific patient-based questionnaires to fully guide the development of interventions intended to improve satisfaction and, in turn, health outcomes.

Finally, although our findings may be convincing for clinicians, they are most likely not sufficient to improve the use of satisfaction assessments in hospitals. ${ }^{30}$ Indeed, previous studies have reported organizational barriers to adequate use of patient satisfaction surveys by care providers, such as a lack of quality management culture and a bureaucratic and hierarchical culture rather than a participative organization. ${ }^{31}$ A greater consideration of consumer satisfaction implies the integration of consumer satisfaction into a continuous quality improvement program, and a change in relationships across the various types of care providers (eg, with the development of multidisciplinary group discussions) in psychiatric hospitals.

\section{Limitations and perspectives}

This study has several limitations. The sample may or may not be representative of all hospitalized patients with schizophrenia. Indeed, our study was performed in two psychiatric hospitals in Marseille, France. Confirmation of our findings is necessary using more diverse and larger groups of patients. Second, the relatively small sample size prevented us from including more confounding factors in the multivariate analyses. Future larger studies should consider this limitation. Third, use of the Clinical Global Impression scale to measure the severity of psychopathology instead of other scales, such as the Positive and Negative Syndrome Scale ${ }^{32}$ (PANSS), may be criticized. While the PANSS has stronger psychometric properties with regard to reliability and validity, the Clinical Global Impression is easier to use and interpret. However, several studies support the extrapolation between the PANSS and Clinical Global Impression scale. ${ }^{33}$ Fourth, the SF36 is a generic quality of life measure and may not adequately capture all areas of functioning and well-being that are relevant to people with schizophrenia. ${ }^{1}$ Future researchers should attempt to replicate our findings using disease-specific quality of life instruments.

Fifth, nonadherence is not easy to detect and quantify, and all methods of detection have some drawbacks. As such, the use of the MARS may be criticized. This scale is a subjective method of assessing compliance in comparison to objective methods such as pill counts, pharmacy records, electronic monitor, and plasma concentrations. However, the MARS has several advantages. It has good psychometric properties and predicts compliance satisfactorily. ${ }^{22}$

Sixth, we performed multiple statistical tests in our analysis that could potentially increase the type I error. However, we consider that the number of statistical tests performed in our study was not excessively high.

Finally, this study is limited by the fact that it was cross-sectional rather than prospective in design. No causal inference can be formally deduced, and our model should be interpreted from an associational point of view. Future studies are needed to establish whether the associations reported herein are longitudinally robust.

\section{Conclusion}

Satisfaction was the only factor associated with quality of life and was one of the most important features associated with nonadherence to medication. These findings confirm the clinical relevance of satisfaction and suggest that it should not be neglected in clinical practice in hospital settings. 


\section{Author contributions}

Study conception and design, XYZ, PA, CL, and LB; study coordination, $\mathrm{XYZ}$; inclusion and collection of clinical data, XYZ; analysis of data, AL, LB; interpretation of data, XYZ, $\mathrm{PA}, \mathrm{KB}$, and LB; and drafting and writing of the manuscript, XYZ, PA, KB, CL, AL and LB.

\section{Acknowledgments}

The authors are grateful to Nathalie Parola and Melanie Faugère for their help and to all the patients who participated in the study. This work was supported by institutional grants from the 2009 Appel Offre-Recherche Clinique Assistance Publique, Hôpitaux de Marseille. The sponsor was represented by Assistance Publique, Hôpitaux de Marseille, France, and its role was to control the appropriate ethical and legal considerations.

\section{Disclosure}

The authors report no conflicts of interest in this work.

\section{References}

1. Boyer L, Baumstarck K, Boucekine M, Blanc J, Lancon C, Auquier P. Measuring quality of life in patients with schizophrenia: an overview. Expert Rev Pharmacoecon Outcomes Res. 2013;13(3):343-349.

2. Boyer L, Baumstarck-Barrau K, Cano N, et al. Assessment of psychiatric inpatient satisfaction: a systematic review of self-reported instruments. Eur Psychiatry. 2009;24(8):540-549.

3. Nair K, Dolovich L, Cassels A, et al. What patients want to know about their medications. Focus group study of patient and clinician perspectives. Can Fam Physician. 2002;48:104-110.

4. Epstein KR, Laine C, Farber NJ, Nelson EC, Davidoff F. Patients' perceptions of office medical practice: judging quality through the patients' eyes. Am J Med Qual. 1996;11(2):73-80.

5. Laine C, Davidoff F, Lewis CE, et al. Important elements of outpatient care: a comparison of patients' and physicians' opinions. Ann Intern Med. 1996;125(8):640-645.

6. Boyer L, Lancon C, Baumstarck K, Parola N, Berbis J, Auquier P. Evaluating the impact of a quality of life assessment with feedback to clinicians in patients with schizophrenia: randomised controlled trial. Br J Psychiatry. 2013;202:447-453.

7. Antoniotti S, Baumstarck-Barrau K, Simeoni MC, et al. Validation of a French hospitalized patients' satisfaction questionnaire: the QSH-45. Int J Qual Health Care. 2009;21(4):243-252.

8. Haute Autorité de Santé. http://www.has-sante.fr/portail/jcms/ r_1439924/fr/manuel-de-certification-des-etablissements-de-santev2010-revise-avril-2011. Haute Autorité de Santé. 2011.

9. Boyer L, Francois P, Doutre E, Weil G, Labarere J. Perception and use of the results of patient satisfaction surveys by care providers in a French teaching hospital. Int J Qual Health Care. 2006;18(5):359-364.

10. Bjorngaard JH, Ruud T, Friis S. The impact of mental illness on patient satisfaction with the therapeutic relationship: a multilevel analysis. Soc Psychiatry Psychiatr Epidemiol. 2007;42(10):803-809.

11. Ware NC, Tugenberg T, Dickey B. Practitioner relationships and quality of care for low-income persons with serious mental illness. Psychiatr Serv. 2004;55(5):555-559.

12. Druss BG, Rosenheck RA, Stolar M. Patient satisfaction and administrative measures as indicators of the quality of mental health care. Psychiatr Serv. 1999;50(8):1053-1058.
13. Bowersox NW, Bohnert AS, Ganoczy D, Pfeiffer PN. Inpatient psychiatric care experience and its relationship to posthospitalization treatment participation. Psychiatr Serv. 2013;64(6):554-562.

14. Chue $P$. The relationship between patient satisfaction and treatment outcomes in schizophrenia. J Psychopharmacol. 2006;20(6 Suppl): 38-56.

15. Evans J, Rose D, Flach C, et al. VOICE: developing a new measure of service users' perceptions of inpatient care, using a participatory methodology. J Ment Health. 2012;21(1):57-71.

16. Avis M. Incorporating patients' voices in the audit process. Qual Health Care. 1997;6(2):86-91.

17. Zendjidjian X, Lancon C, Auquier P, Boyer L. The SATISPSY-22: development and validation of a French hospitalized patients' satisfaction questionnaire in psychiatry. Eur Psychiatry. In press 2014.

18. World Medical Association. Declaration of Helsinki, 6th Revision. Edinburgh, UK: World Medical Association; 2008.

19. Guy W. ECDEU Assessment Manual for Psychopharmacology. Rockville, MD, USA: US Department of Health, Education, and Welfare; 1976.

20. Endicott J, Spitzer RL, Fleiss JL, Cohen J. The global assessment scale. A procedure for measuring overall severity of psychiatric disturbance. Arch Gen Psychiatry. 1976;33(6):766-771.

21. Ware JE Jr, Sherbourne CD. The MOS 36-item short-form health survey (SF-36). I. Conceptual framework and item selection. Med Care. 992;30(6):473-483.

22. Fialko L, Garety PA, Kuipers E, et al. A large-scale validation study of the Medication Adherence Rating Scale (MARS). Schizophr Res. 2008;100(1-3):53-59.

23. Lasalvia A, Boggian I, Bonetto C, et al. Multiple perspectives on mental health outcome: needs for care and service satisfaction assessed by staff, patients and family members. Soc Psychiatry Psychiatr Epidemiol. 2011;47(7):1035-1045.

24. Boyer L, Millier A, Perthame E, Aballea S, Auquier P, Toumi M. Quality of life is predictive of relapse in schizophrenia. BMC Psychiatry. 2013; $13: 15$.

25. Dassa D, Boyer L, Benoit M, Bourcet S, Raymondet P, Bottai T. Factors associated with medication nonadherence in patients suffering from schizophrenia: a cross-sectional study in a universal coverage health-care system. Aust N Z J Psychiatry. 2010;44(10):921-928.

26. Boyer L, Cermolacce M, Dassa D, et al. Neurocognition, insight and medication nonadherence in schizophrenia: a structural equation modeling approach. PLoS One. 2012;7(10):e47655.

27. Leucht S, Heres S. Epidemiology, clinical consequences, and psychosocial treatment of nonadherence in schizophrenia. J Clin Psychiatry. 2006; 67 Suppl 5:3-8.

28. Patrick DL, Deyo RA. Generic and disease-specific measures in assessing health status and quality of life. Med Care. 1989;27 (3 Suppl):S217-S232.

29. Wiebe S, Guyatt G, Weaver B, Matijevic S, Sidwell C. Comparative responsiveness of generic and specific quality-of-life instruments. $J$ Clin Epidemiol. 2003;56(1):52-60.

30. Deyo RA, Patrick DL. Barriers to the use of health status measures in clinical investigation, patient care, and policy research. Med Care. 1989;27(3 Suppl):S254-S268.

31. Shortell SM, O'Brien JL, Carman JM, et al. Assessing the impact of continuous quality improvement/total quality management: concept versus implementation. Health Serv Res. 1995;30(2):377-401.

32. Kay SR, Fiszbein A, Opler LA. The Positive and Negative Syndrome Scale (PANSS) for schizophrenia. Schizophr Bull. 1987;13(2):261-276.

33. Levine SZ, Rabinowitz J, Engel R, Etschel E, Leucht S. Extrapolation between measures of symptom severity and change: an examination of the PANSS and CGI. Schizophr Res. 2008;98(1-3):318-322. 


\section{Supplementary materials}

Supplement I List of 22-Satispsy items (English version)

\begin{tabular}{|c|c|}
\hline Item number & English item, general meaning \\
\hline I & I received sufficient information about the hospital stay (consultations and care planning, drug delivery ...) \\
\hline 2 & I felt anxious or stressed while in the ward \\
\hline 3 & I thought the service provided enough activities and patient entertainment \\
\hline 4 & I felt lonely and isolated \\
\hline 5 & I felt that staff were available when I needed them \\
\hline 6 & I thought the quality of the food was good \\
\hline 7 & My disorder has been adequately treated \\
\hline 8 & I trusted the medical staff \\
\hline 9 & My treatment was suitably adjusted to suit me \\
\hline 10 & I found the staff respectful \\
\hline 11 & I've been informed of the how the service functions (visiting hours, discharge process ...) \\
\hline 12 & I felt that staff were available \\
\hline 13 & I thought the range of proposed activities was broad enough \\
\hline 14 & The treatment was positive overall and benefited me \\
\hline 15 & I felt imprisoned \\
\hline 16 & I thought the food was sufficiently abundant \\
\hline 17 & I felt that staff listened to me \\
\hline 18 & I am in better condition now than when I was admitted \\
\hline 19 & I felt deprived of my freedom \\
\hline 20 & I thought the staff were helpful \\
\hline 21 & I received the right treatment \\
\hline 22 & I thought the staff were competent \\
\hline
\end{tabular}

Supplement 2 List of 37-QSH items (English version)

\begin{tabular}{|c|c|}
\hline Item number & English item general meaning \\
\hline & When arriving at the hospital ... \\
\hline I & Administrative staff registered me quickly \\
\hline 2 & Administrative staff was helpful and kind \\
\hline \multirow[t]{2}{*}{3} & I felt the coordination between administrative wards was good \\
\hline & When arriving at the department/ward ... \\
\hline 4 & Health professional providers took me in quickly \\
\hline 5 & Health professional providers welcomed me heartily \\
\hline \multirow[t]{2}{*}{6} & I believed that the staff knew that I was arriving \\
\hline & During my hospital stay, the medical staff ... \\
\hline 7 & Identified themselves (name, function) \\
\hline 8 & Communicated with me in a comprehensive manner \\
\hline 9 & Gave me attention and considered my needs \\
\hline 10 & Won my trust and reassured me \\
\hline 11 & Regularly came to see me \\
\hline 12 & Came each time I needed them \\
\hline 13 & Gave me full attention \\
\hline \multirow[t]{2}{*}{14} & Answered all of my questions \\
\hline & During my hospital stay, the nursing staff ... \\
\hline 15 & Identified themselves (name, function) \\
\hline 16 & Communicated with me in a comprehensive manner \\
\hline 17 & Gave me attention and considered my needs \\
\hline 18 & Won my trust and reassured me \\
\hline 19 & Gave me full attention \\
\hline \multirow[t]{2}{*}{20} & Shared information about myself \\
\hline & with other nurses \\
\hline 21 & Helped me with daily activities \\
\hline \multirow[t]{2}{*}{22} & Respected my privacy \\
\hline & During my hospital stay, the other staff ... \\
\hline
\end{tabular}




\section{Supplement 2 (Continued)}

\begin{tabular}{|c|c|}
\hline 23 & Identified themselves (name, function) \\
\hline 24 & Gave me attention and considered my needs \\
\hline 25 & Quickly came in my room when needed \\
\hline 26 & Kindly welcomed me \\
\hline 27 & Helped me with daily activities \\
\hline \multirow[t]{2}{*}{28} & Conscientiously did their work \\
\hline & During my hospital stay, the waiting time was ... \\
\hline 29 & Before going or coming back from clinics, operating rooms \\
\hline \multirow[t]{2}{*}{30} & When being received in clinics, operating room \\
\hline & During my hospital stay, my room ... \\
\hline 31 & Was appropriately cleaned \\
\hline \multirow[t]{2}{*}{32} & Was well equipped \\
\hline & During my hospital stay, the rest rooms ... \\
\hline 33 & Were appropriately cleaned \\
\hline \multirow[t]{2}{*}{34} & Were in or close to my room \\
\hline & During my hospital stay, the food ... \\
\hline 35 & Was of good quality \\
\hline 36 & Was of sufficient quantity \\
\hline 37 & Was adapted to my needs (treatments, comorbidities ...) \\
\hline
\end{tabular}

\section{Publish your work in this journal}

Patient Preference and Adherence is an international, peer-reviewed, open access journal that focusing on the growing importance of patient preference and adherence throughout the therapeutic continuum. Patient satisfaction, acceptability, quality of life, compliance, persistence and their role in developing new therapeutic modalities and compounds to optimize clinical outcomes for existing disease states are major areas of interest for the journal. This journal has been accepted for indexing on PubMed Central The manuscript management system is completely online and includes a very quick and fair peer-review system, which is all easy to use. Visit http://www. dovepress.com/testimonials.php to read real quotes from published authors.

\footnotetext{
Submit your manuscript here: http://www.dovepress.com/patient-preference-and-adherence-journal
} 